\title{
Deficiência mental e produção científica na base de dados da CAPES: o lugar da aprendizagem
}

\author{
Pesquisas sobre deficiência mental
}

\author{
Alexandra Ayach Anache \\ Albertina Martinez Mitjáns
}

\section{Resumo}

Este trabalho tem como objetivo realizar um levantamento das pesquisas sobre a deficiência mental e a partir dessa caracterização, compreender o lugar que nela ocupam as pesquisas direcionadas ao processo de aprendizagem da população com deficiência mental. Para este fim, pesquisamos produções acadêmicas em nível de mestrado e de doutorado no período de 1990 até 2005/2006, registradas no Banco de Teses do Portal da Fundação Coordenação de Aperfeiçoamento de Pessoal de Nível Superior (CAPES), que faziam referência à deficiência mental, bem como era o assunto privilegiado por elas. A análise de conteúdo dos resumos permitiu obter informações sobre a data, o locus das pesquisas, o tema tratado e $\circ$ direcionamento teórico e metodológico. Foram encontradas 122 referências, sendo 38 dissertações e 84 teses. No conjunto dessas produções, os assuntos relacionados à avaliação e ao diagnóstico, ao ensino, às interações sociais, à saúde, à inclusão e à avaliação educacional foram os temas mais contemplados. $O$ tema aprendizagem foi abordado em $6 \%$ dos trabalhos (7), demonstrando a necessidade de se construir estratégias para compreensão e aprofundamento desse aspecto visto que ele foi tratado de forma tímida pela academia brasileira. Os resumos das pesquisas assinalam resultados promissores sobre as possibilidades de aprendizagem dos alunos com deficiência mental.

Palavras-chave: deficiência mental; aprendizagem; produções acadêmicas.

\section{Mental deficiency and scientific production in the CAPES database: the place of apprenticeshipabstract}

\begin{abstract}
This paper has for its objective the data collection of research on mental deficiency and, from this characterization, the comprehension of the place occupied by research directed to the learning process of members of this group. We analyze the theoretical and methodological orientation of academic production at master's and doctoral levels during the 1990 to 2005/2006 registered in the Theses Bank of the Portal da Fundação Coordenação de Aperfeiçoamento de Pessoal de Nível Superior [CAPES]. We had found 122 references, 38 dissertations and 84 theses. On the whole, the topics dealt with evaluation and diagnosis, teaching, social interaction, health, inclusion and educational evaluation were the most cited. Learning accounted for $6 \%$ of the works (7), demonstrating the necessity for constructing strategies for the comprehension and deepening of this aspect, given the timid form of treatment by the Brazilian academia.
\end{abstract}

Keywords: mental retardation; learning; scientific research.

\section{Deficiencia mental y producción científica en la base de datos del CAPES: el lugar del aprendizaje}

\begin{abstract}
Resumen
Este trabajo tiene como objetivo realizar un levantamiento de las investigaciones sobre la deficiencia mental y a partir de esa caracterización entender el lugar que ocupan en ella las investigaciones dirigidas al proceso de aprendizaje de la población con deficiencia mental. Para ese fin investigamos producciones académicas a nivel de maestría y de doctorado en el período de 1990 hasta 2005/2006 registradas en el Banco de Teses del Portal de la Fundação Coordenação de Aperfeiçoamento de Pessoal de Nível Superior (CAPES), que hacían referencia a la deficiencia mental, así como tambien era el asunto privilegiado por ellas. El análisis de contenido de los resúmenes permitió obtener informaciones sobre la fecha, el locus de la investigación, el tema tratado y el direccionamiento teórico y metodológico. Fueron encontradas 122 referencias, siendo 38 de maestría y 84 de doctorado. En el conjunto de esas producciones, los asuntos relacionados a la evaluación y al diagnóstico, a la enseñanza, a las interacciones sociales, a la salud, a la inclusión y a la evaluación educacional fueron os temas más contemplados. El tema aprendizaje fue abordado en $6 \%$ de los trabajos (7), demostrando la necesidad de construir estrategias para la comprensión y la ampliación de ese aspecto, una vez que fue tratado de forma tímida por la academia brasileña. Los resúmenes de las investigaciones señalan resultados positivos sobre las posibilidades de aprendizaje de los alumnos con deficiencia mental.
\end{abstract} Palabras clave: deficiencia mental; aprendizaje; producciones académicas 


\section{Introdução}

Este artigo apresenta um levantamento das pesquisas sobre deficiência mental e a partir dessa caracterização, compreende-se o lugar que nela ocupam as pesquisas direcionadas ao processo de aprendizagem da população em questão. Dentre os fatores que justificam este estudo, destaca-se a necessidade de analisar o direcionamento teórico e metodológico que as produções acadêmicas, tanto em nível de mestrado quanto de doutorado, têm construído no período de 1990 a 2005/2006 a fim de delinear estratégias pedagógicas que contribuam de modo efetivo para a aprendizagem e, conseqüentemente, para o desenvolvimento da população com deficiência mental.

Desde Itard (I80I-|806), há iniciativas na promoção do ensino formal para a população com deficiência mental, muitas delas registradas, e que geraram o acúmulo de conhecimentos em diferentes tempos históricos. No entanto, ainda há interrogações sobre as possibilidades de aprendizagem de pessoas com deficiência mental, o que justifica o interesse dos pesquisadores nessa área.

O levantamento das produções que se ocuparam em realizar um diagnóstico geral sobre o conhecimento acumulado em Educação começa a surgir no Brasil a partir de 1970, nos trabalhos de: Gouveia (197I), Almeida (1972), Di Dio (1976), Cunha (1979), Goergen (198I), Sanches (1982 e 1987), Gatti (1983), Feldens (1983), Warde (1992), Weber (1992) e Costa (1994) e, mais recentemente, de Lima (2003). No que se refere especificamente à Educação Especial, destacam-se Dias e colaboradores (1987), Nunes, Glat, Ferreira e Mendes (1998), Nunes, Ferreira e Mendes (2003) e Bueno (2006).

Sobre a deficiência mental, Silva, Vidal e Sousa (2003) realizaram um levantamento das pesquisas desenvolvidas nos Programas de Pós-Graduação stricto sensu em Educação Física e Esporte situados na Região Sudeste do Brasil, no período de 1979 a 2002. Esses autores identificaram as tendências das temáticas estudadas bem como as implicações teóricas e práticas dessa produção. Eles encontraram, dentre os 1065 trabalhos produzidos no período pesquisado (952 dissertações e 113 teses), I5 que tratavam do tema deficiência mental (14 dissertações e uma tese), o que significa I,5\% de dissertações realizadas nos Programas de Mestrado e $0,9 \%$ de teses nos Programas de Doutorado. Para os autores esse número foi considerado inexpressivo.

Bueno (2006) analisou as inserções dos conceitos de inclusão escolar e de educação inclusiva, encontrando 127 dissertações e teses, sendo que 12,6\% delas tratavam de temas relacionados à deficiência mental. Mais da metade das produções não explicitava o tipo de deficiência estudada, mencionando tão-somente que pesquisavam as "deficiências" ou as "necessidades educativas especiais". Diante do exposto, Bueno observou que tais ambigüidades decorrem tanto das formulações políticas quanto da produção acadêmica recente, expressa pelas dissertações e teses defendidas no período compreendido entre 1997 e 2003, constantes do Banco de Teses da CAPES.

Note-se que as pesquisas dos autores supracitados oferecem um panorama geral da produção acerca da Educação Especial e assuntos correlatos. No entanto, nossa preocupação neste momento é obter informações sobre o lugar ocupado pelos estudos sobre aprendizagem da população com deficiência mental no conjunto dos trabalhos. Assim, optou-se por analisar os resumos dos trabalhos de pesquisa produzidos nos últimos 15 anos uma vez que foi nesse período que a educação de pessoas com deficiência aparece nos discursos oficiais com maior ênfase.

No Brasil, esse movimento surgiu nos anos de 1980 , quando as lideranças da área começaram a questionar a base ética, a eficácia da lei e a prática de integração, pois estas, de fato, se mostravam segregadoras, considerando que imputavam ao sujeito à responsabilidade de movimentar-se para conseguir adaptação nos diferentes setores da sociedade.

Após a promulgação da lei $n^{\circ}$ 9394, de 20 de dezembro de 1996, que estabeleceu as diretrizes e as bases da Educação Nacional, assegurando a educação das pessoas que apresentam necessidades especiais, preferencialmente na rede regular de ensino, a Secretaria de Educação Especial, por meio da Coordenadoria Geral de Planejamento do Ministério da Educação, registrou, no período de 1998 a 2005, 
um aumento de $20 \%$ de matrículas de estudantes com deficiência em escolas de ensino comum. Das 278.167 pessoas com deficiência mental, 141.868 (5I\%) estavam matriculadas em escolas públicas e 136.299 (49\%) em escolas privadas (cf. Brasil. Ministério da Educação, INEP, SEEC. Censo Escolar, 2004).

No entanto, o documento da Secretaria de Educação Especial não esclarece se os estudantes matriculados nas escolas de ensino comum freqüentavam classes especiais ou a sala de recursos. No que se refere às escolas da iniciativa privada, não se sabe, pelo documento oficial, se elas eram ou não de organizações não-governamentais, conforme ilustra o título da Tabela sobre a distribuição de matrículas na Educação Especial em 2005, Matrículas em Escolas Especiais/Classes Especiais e Escolas Regulares/Classes Comuns ( $c f ;$ p. 6). Além disso, não se sabe a situação educacional das pessoas que apresentam deficiências mentais mais graves ou severas (cf. Brasil. Ministério da Educação. Secretaria de Educação Especial. Coordenação Geral de Planejamento, 2006).

O tema em discussão carece de maiores e melhores estudos uma vez que no conjunto das produções da área de Educação seu número ainda não pode ser considerado expressivo. Silva e cols. (2003, p. 16), em suas pesquisas, demonstraram que as teses e as dissertações relacionadas à temática deficiência mental, realizadas no período de 1979 a 2002, referemse a I,4\% do total de trabalhos defendidos nos Programas de Pós-Graduação na área de Educação Física e Esporte da Região Sudeste. Ao analisarem os tipos de deficiência mais estudados, Manzini, Paulino, Corrêa, Silva e Lopes (2006) identificaram uma produção maior em deficiência física (I I), em todas as deficiências (10) e na deficiência mental (9) no Programa de Pós-Graduação da Universidade Estadual Paulista (UNESP) - Campus de Marília - no período de 1993 a 2004.

Se, por um lado, o tema deficiência mental não tem sido tratado com expressividade no conjunto das produções da área de Educação Física, por outro, ele preocupa os pesquisadores da área de Educação, pois é a pessoa com deficiência mental quem tem causado maiores dificuldades à prática cotidiana dos professores nas escolas (comum e especial), em decorrên- cia das dificuldades aferidas no processo ensino-aprendizagem.

Segundo os estudos realizados por Bueno (2002), em 1998, tínhamos 127 trabalhos de pesquisa produzidos nas Instituições de Ensino Superior, sendo 83 deles referentes às deficiências de modo geral. Desse conjunto, a deficiência mental e a auditiva foram as mais contempladas. Nos últimos 15 anos, no conjunto das produções que trataram dos estudos sobre as deficiências, predominaram as pesquisas que versam sobre a deficiência mental, coincidindo com as informações obtidas por Bueno (2006), ao pesquisar as produções acadêmicas que tratavam do tema inclusão. Ele encontrou, entre os 127 resumos de trabaIhos analisados, 16 que se referiam à deficiência mental $(12,6 \%)$ e 10 destinados à deficiência física (7,09\%). O autor não conseguiu identificar a população-alvo em 67 (57,75\%) dos resumos analisados. Ele concluiu que essa incidência acompanhava os resultados já obtidos por outros autores, que realizaram o mesmo tipo de pesquisa, dentre eles, Nunes e cols. (1998 e 2003).

Bueno (2006) identificou também que a deficiência mental vem associada às dificuldades de aprendizagem. Este fator pode justificar a incidência das produções sobre a deficiência mental que visaram contribuir com temas relacionados ao ensino, à avaliação, às interações sociais e à saúde.

A Secretaria de Educação Especial, por meio da Coordenadoria Geral de Planejamento do Ministério da Educação, divulgou no documento Números da Educação Especial, em janeiro de 2006, que das 350.000 matrículas de alunos (as) com necessidades educacionais especiais, 278.167 (43,4\%) ainda eram de pessoas com deficiência mental, o que pode justificar a demanda por pesquisas na área.

\section{Método}

O locus de pesquisa foi o Portal da Fundação Coordenação de Aperfeiçoamento de Pessoal de Nível Superior (CAPES)', que integra os sistemas de informação de teses e de dissertações existentes nas Instituições de Ensino Superior brasileiras, 
reunindo os trabalhos científicos em seu banco de dados.

Quando se acessa o Banco de Dados da CAPES com a palavra-chave deficiência mental, encontram-se várias denominações para essa mesma expressão, com destaque para necessidades especiais, paralisia cerebral, deficiência cognitiva, deficiência intelectual e doenças infecto-contagiosas. Ainda que o propósito do Banco de Dados seja o de agrupar o maior número de trabalhos relacionados à área, há que ressaltar as dificuldades conceituais, que merecem discussões.

Vale esclarecer que a deficiência mental é uma condição que se manifesta no curso do desenvolvimento da pessoa, resultando em dificuldades para processar informações, conceituar, avaliar, estabelecer relações conceituais, linguagem, entre outras, que podem se expressar em diferentes áreas que não apenas a acadêmica. Necessidade educacional especial não é sinônimo de deficiência bem como nem toda pessoa com paralisia cerebral apresenta deficiência mental.

De posse dos títulos dos 122 trabalhos encontrados, aconteceu à busca dos resumos na Base de Dados da CAPES, visando caracterizar as produções sobre a deficiência mental. Desse conjunto, 86 deles apresentavam os resumos, os quais constituem o corpus desta análise, expressando $70 \%$ do total pesquisado.

As produções foram identificadas pelos seguintes aspectos: número de dissertações e de teses registradas no período escolhido; instituição de origem; objeto específico para estudo e os itens que compõem o resumo dos trabalhos científicos, quais sejam: o tema, o objeto, a abordagem teórica e metodológica, os instrumentos e a síntese dos resultados. Essas informações foram fundamentais para a construção do primeiro eixo de análise identificado como a inserção da deficiência mental como tema de referência nas produções acadêmicas.

Os títulos e os conteúdos (objeto de estudo e objetivos), contidos nos resumos analisados, identificaram as pesquisas de acordo com o assunto. $\mathrm{Na}$ incerteza sobre a classificação das informações, recorria-se à dissertação ou à tese. As produções acadêmicas que tratam dos processos de aprendizagem de pessoas que apresentam deficiência mental foram as selecionadas, o que determinou a elaboração do segundo eixo de análise: o lugar da aprendizagem nas produções acadêmicas registradas na Base de Dados, escolhida para esta pesquisa. A análise foi conduzida, entendendo que a aprendizagem é um processo de subjetividade individual e social, portanto, relacional (cf. González Rey, 2005).

\section{Resultados e Discussão}

\section{A inserção da deficiência mental como tema de referência nas produções acadêmicas \\ O levantamento das produções acadêmicas} disponibilizadas na Base de Dados - IBICT/Portal da CAPES, no período em que a pesquisa foi realizada, possibilitou encontrar 38 dissertações e 84 teses, perfazendo um total de 122 produções tratando de estudos sobre a deficiência mental nos últimos 15 anos.

Pode-se observar um aumento progressivo nas produções acadêmicas na área, sendo mais expressivo no período de 2000 a 2005 . Esse fato pode ser associado aos movimentos sociais em prol dos direitos humanos, manifestados no âmbito internacional e nacional, neste caso, após a Ditadura Militar bem como à expansão dos Programas de Pós-Graduação no Brasil.

A expansão da Pós-Graduação stricto sensu no País ainda é recente, sobretudo no que se refere aos Programas em nível de doutorado, o que justifica $\circ$ acúmulo de dissertações produzidas no certame do período pesquisado. Manzini, Paulino, Corrêa, Silva e Lopes (2006) afirmam que o incremento da produção na área de Educação Especial na UNESP - Campus de Marília - decorreu do aumento do número de orientadores nessa linha até 200I, o que pode ser relacionado ao aumento dos cursos de Pós-Graduação stricto sensu.

A Pós-Graduação em nível de mestrado e de doutorado iniciou-se no Brasil nos meados dos anos de 1960 e, desde então, tem se expandido. Segundo os registros oficiais fornecidos pela CAPES, existem no Brasil 2.284 Programas e Cursos de Pós-Graduação recomendados e reconhecidos, sendo que há 929 mestrados acadêmicos, 42 doutorados e 175 mestrados profissionais. Há I.I 38 Programas de Pós- 
Tabela I. Dissertações e teses sobre deficiência mental, registradas na BDTD (IBICT)/Portal CAPES (1990-2005/2006)

\begin{tabular}{crrrrrr}
\hline \hline \multirow{2}{*}{ Ano } & \multicolumn{2}{c}{ Teses } & \multicolumn{2}{c}{ Dissertações } & \multicolumn{2}{c}{ Total } \\
\cline { 2 - 7 } 1990 & 0 & 0,0 & 0 & 0,0 & 0 & 0 \\
1991 & 0 & 0,0 & 0 & 0,0 & 0 & 0 \\
1992 & 2 & 2,4 & 0 & 0,0 & 2 & 2 \\
1993 & 2 & 2,4 & 2 & 5,3 & 4 & 3 \\
1994 & 4 & 4,8 & 2 & 5,3 & 6 & 5 \\
1995 & 3 & 3,6 & 1 & 2,6 & 4 & 2 \\
1996 & 0 & 0,0 & 0 & 0,0 & 0 & 0 \\
1997 & 4 & 4,8 & 3 & 7,9 & 7 & 6 \\
1998 & 6 & 7,1 & 3 & 7,9 & 9 & 7 \\
1999 & 5 & 6,0 & 1 & 2,6 & 6 & 5 \\
2000 & 6 & 7,1 & 6 & 15,8 & 12 & 10 \\
2001 & 10 & 12,0 & 5 & 13,2 & 15 & 12 \\
2002 & 6 & 7,1 & 5 & 13,2 & 11 & 9 \\
2003 & 7 & 7,1 & 5 & 13,2 & 12 & 10 \\
2004 & 10 & 12,0 & 3 & 7,9 & 13 & 11 \\
2005 & 9 & 11,0 & 1 & 2,6 & 10 & 10 \\
2006 & 6 & 7,1 & 1 & 2,6 & 7 & 6 \\
s/data & 4 & 4,8 & 0 & 0 & 4 & 2 \\
\hline Total & 84 & 99,9 & 38 & 100 & 122 & 100 \\
\hline
\end{tabular}

Graduação em nível de mestrado acadêmico e de doutorado.

A título de ilustração, em 1998, funcionavam 46 Cursos de Pós-Graduação em Educação em nível de mestrado e 21 em nível de doutorado (cf. Nunes e cols., 1998). Em 19 de setembro de 2006, a CAPES registrava 118 Programas de Pós-Graduação em Educação, sendo 82 mestrados e 36 doutorados.

Naquela mesma data, o órgão supracitado registrava 87 Cursos de Pós-Graduação na área de Psicologia, sendo 56 mestrados e 31 doutorados. $\mathrm{Na}$ grande área das Ciências da Saúde, na qual a Educação Física está inserida, registraram-se 680 Cursos dessa natureza, distribuídos em 377 mestrados e 264 doutorados. Em hipótese, a expansão desses Cursos jus- tificou as iniciativas de outras áreas do conhecimento em estudar a temática em pauta neste artigo, como as áreas de Engenharia (Engenharia de Produção $2 \%)$ e Letras (2\%).

A área de Ciências Humanas englobou o maior número de produções sobre a deficiência mental seguida das Ciências da Saúde e das Ciências Biológicas. Notou-se que os Programas de Pós-Graduação em Educação, incluindo os específicos em Educação Especial, tributaram $55 \%$ das produções de teses e de dissertações que tratam da temática pesquisada.

Vale registrar que no Brasil tem se especificamente dois Cursos de Pós-Graduação stricto sensu em Educação Especial. Nos demais, a educação especial insere-se na Pós-Graduação como linha de pesquisa, 
ou como objeto de estudo de outras áreas do conhecimento. Sobre a inserção da Educação Especial em Programas de doutorado, Bueno (2002, p. 57) informa que em 1998 havia um Curso nesse nível mantido pela Universidade Federal do Rio Grande do Norte e um pela Universidade Federal Fluminense. $50 \%$ dos Programas estavam localizados na cidade de São Paulo e incorporavam alunos de Educação Especial.

Quando Bueno (2002) realizou o levantamento das produções acadêmicas que versavam sobre a Educação Especial, ele encontrou 23 Instituições de Ensino Superior que possuíam Cursos de Pós-Graduação stricto sensu, em nível de mestrado, que aceitavam estudantes desejosos de desenvolver suas pesquisas com temas na área de referência. Ele registrou ainda que apenas dois deles ofereciam mestrado em Educação Especial. Essa pesquisa informou ainda que "[...] dos 21 mestrados em educação, quase dois terços (13) aceitam alunos nas Linhas de Pesquisas por elas mantidas, cerca de um terço (8) possui Linha de Pesquisa específica em educação especial” (Bueno, 2002, p.53).

Assim, a organização dos Programas de Pós-Graduação stricto sensu pode ser um dos indicadores da necessidade de aprimoramento da formação de profissionais para atuação com pessoas que apresentam deficiência. Bueno (1999) esclarece que não há oposição entre uma proposta de curso generalista ou especialista, pois a perspectiva da educação inclusiva exige que o docente do ensino comum adquira conhecimentos especializados para atender à demanda de estudantes com características peculiares e, do mesmo modo, o professor da Educação Especial precisa ampliar sua compreensão que, tradicionalmente, está centrada nessas características.

No que se refere ao locus da produção, constatou-se a ampliação da oferta de Cursos de Pós-Graduação stricto sensu nas diversas regiões do País, fora do eixo Rio de Janeiro e São Paulo. A título de ilustração, os Cursos de Pós-Graduação stricto sensu estão distribuídos nas regiões do Brasil com os seguintes números: Região Sudeste do Brasil: I.195; Região Sul: 456; Região Nordeste: 385; Região Centro-Oeste: 156; e Região Norte: 92. No entanto, a concentração das produções está nas Universidades do Estado de São Paulo, fato que pode ser atribuído ao número de Instituições de Ensino Superior presentes nesse Estado. Acres. Além disso, os Cursos que incorporaram a Educação Especial estão situados preponderantemente nas Regiões Sudeste, com 56,5\%, e Sul, com $21,7 \%$, de um total de 23 Programas de PósGraduação mencionados.

Os temas mais encontrados no conjunto dos 122 trabalhos foram os relacionados à avaliação e ao diagnóstico, ao ensino, às interações sociais, à inclusão e à saúde. Os demais foram referenciados com menor freqüência; no entanto, isso não significa que eles sejam menos importantes para a área. Cabe-nos aqui compreender de que forma eles foram estudados, conforme a Tabela 2.

Avaliação e diagnóstico foram os trabalhos identificados que estudaram os encaminhamentos bem como os recursos metodológicos utilizados pelos profissionais que avaliam pessoas que apresentam indicadores de deficiência mental.

Em um período de 15 anos (1990-2005/2006), 17\% do conjunto de dissertações e de teses tratam de temas relacionados ao processo de avaliação e de diagnóstico da deficiência mental. Observou-se que houve um acréscimo de teses e um decréscimo em produções de dissertações sobre o tema. Tal indicador pode ser atribuído ao maior número de Programas de mestrado do que de doutorado no Brasil e a conseqüente pulverização de interesses dos pesquisadores.

Quando Nunes e colaboradores (1998) analisaram - conjunto das produções realizadas na Região Sudeste no período de 1983 e 1996, eles identificaram um decréscimo de dissertações e sugeriram que esse fato poderia ser conseqüência do avanço das produções científicas que versavam sobre estratégias para a identificação de pessoas com deficiência. Contudo, eles também registraram que o diagnóstico para fins educacionais foi pouco estudado.

Segundo os autores supracitados, os trabalhos anunciavam a necessidade de aprofundamento dos critérios de identificação e de encaminhamento de pessoas com deficiência mental para os serviços especiais, e da urgência da realização de pesquisas de caráter metodológico, para a intervenção na realidade. Assim, o aumento do número de teses produzi- 
Tabela 2. Objeto de Estudo das dissertações e teses sobre deficiência mental registradas na BDTD (IBICT) /Portal CAPES (1990-2005/2006)

\begin{tabular}{lrrrrrr}
\hline \multirow{2}{*}{ Temas } & \multicolumn{2}{c}{ Dissertações } & \multicolumn{2}{c}{ Teses } & \multicolumn{2}{c}{ Total } \\
\cline { 2 - 7 } & \multicolumn{1}{c}{ F } & \multicolumn{1}{c}{$\%$} & F & $\%$ & F & $\%$ \\
\hline Avaliação e diagnóstico & 13 & 15 & 7 & 18 & 20 & 16 \\
Ensino & 11 & 13 & 6 & 16 & 17 & 14 \\
Interações sociais & 11 & 3 & 3 & 8 & 14 & 11 \\
Saúde & 9 & 11 & 5 & 13 & 14 & 11 \\
Inclusão & 12 & 14 & 1 & 3 & 13 & 11 \\
Avaliação educacional & 9 & 11 & 0 & 0 & 9 & 7 \\
Sujeito com deficiência mental & 4 & 5 & 4 & 11 & 8 & 7 \\
Formação de profissionais & 3 & 4 & 4 & 11 & 7 & 6 \\
Ensino-aprendizagem & 4 & 5 & 2 & 5 & 6 & 5 \\
Formação para o trabalho & 2 & 2 & 3 & 8 & 5 & 4 \\
Sexualidade & 2 & 2 & 2 & 5 & 4 & 3 \\
Tecnologia da informação e & 2 & 2 & 0 & & 2 & 2 \\
comunicação & & & & & & 1 \\
Constituição do sujeito & 0 & 0 & 1 & 3 & 1 & 100 \\
\hline Total & 84 & 100 & 38 & 100 & 122 & \\
\hline
\end{tabular}

das no período de 1994 a 2004 pode ser uma decorrência dessa necessidade.

Pesquisas como as de Patto (199I), Machado (1994), Machado e Sousa (1997) e Anache (1997) já apresentavam críticas ao sistema de diagnóstico de encaminhamento de alunos (as) para as classes especiais, ou seja, já verificavam que a classe especial abrigava alunos cujo diagnóstico de deficiência mental não atendia aos critérios estabelecidos pela American Psychiatric Association, aqueles descritos no DSM-IV-TM (1995, p.45).

As críticas produzidas no conjunto dos trabalhos, bem como os movimentos sociais de inclusão, colocaram sob suspeita os diagnósticos dos alunos (as) que estavam matriculados (as) nas classes especiais como também o sistema de avaliação educacional empregado pelas escolas brasileiras. As produções de Patto (1991), Machado (1994) Machado e Sousa (1997) e Anache (1997) problematizavam os métodos empregados para a identificação de estudantes com deficiência mental.

Embora as críticas realizadas pelas pesquisas sobre os diagnósticos classificatórios tenham sido opor- tunas, alguns problemas não foram resolvidos, dentre eles, a necessidade de construção de outras formas de avaliação de pessoas com deficiência mental, capazes de oferecer informações sobre os seus processos de aprendizagem.

Quanto aos resumos dos trabalhos agrupados com - tema ensino, eles tratam do currículo; da prática docente na aula, na escola e em outros espaços institucionais; dos projetos pedagógicos e das propostas de intervenções pedagógicas que visam analisar e construir estratégias metodológicas para promover a aprendizagem de estudantes com deficiência mental.

Vale ressaltar os esforços dos pesquisadores em colocar em pauta $\circ$ tema ensino, posto que esse assunto surge nos trabalhos produzidos no período de 1992 a 2005, perfazendo um total de $14 \%$ das produções acadêmicas. Dentre eles, Franco (2002) e Rossit (2003) registraram a eficácia do uso da Informática como recurso alternativo para a promoção do ensino das pessoas com deficiência mental. 
Machado (2000) estudou uma proposta de educação ambiental, resultante de uma experiência com adolescentes e adultos com deficiência mental. Solér (200I) pesquisou sobre o processo de alfabetização e suas relações com a construção do conhecimento, um estudo em deficiência mental leve.

Maranhe (2004) propôs o ensino de categorias estruturais de histórias para crianças com dificuldades de aprendizagem por meio da aplicação dos programas de ensino, e observou uma melhora no desenvolvimento dos grupos de crianças com e sem dificuldades de aprendizagem, principalmente nas produções orais e no recontar das histórias.

Tini (2004) analisou o ensino por modelação de discriminações condicionais, envolvendo diferentes estruturas de treino e de formação de classes de equivalência em deficientes mentais. A pesquisadora constatou que é possível ensinar a essas crianças discriminações condicionais por meio de modelação de estímulos. Nesse mesmo referencial, Sella (2005) estudou o ensino de discriminações condicionais por imitação, analisando os efeitos de dois arranjos de apresentação de tentativas, observando que há possibilidades de ensinar por imitação, comportamentos complexos, pois a maioria dos participantes apresentou aprendizagem por equivalência.

Silva (2003) identificou os jogos e os brinquedos disponíveis e mais utilizados nas brincadeiras de crianças com deficiência mental em escolas especiais da educação infantil bem como o lugar ocupado por essas brincadeiras no processo de ensino. Miranda (2003) analisou a prática pedagógica de duas professoras do Ensino Fundamental, sendo uma da escola comum da rede municipal e a outra da escola especial que tem alunos com deficiência mental freqüentando as suas salas de aulas. Por meio do estudo etnográfico, constatou-se que as referidas práticas não permitiam o desenvolvimento do pensamento abstrato, pois eram repetitivas, mecânicas e descontextualizadas. Essa é uma crítica realizada pela maioria dos trabaIhos realizados com o tema ensino.

Já o tema interações sociais, englobou produções que analisaram e discutiram as relações estabelecidas entre as pessoas com deficiência mental e seus familiares, professores, colegas de escola, de trabalho e de outros espaços sociais. No período de 1992 a 2006, encontram-se produções que apresentaram análises sobre as interações sociais, seja na escola comum, seja na escola especial, na família ou no trabaIho, uma tentativa de buscar alternativas para se ensinar, conviver e viver junto como cidadão de direitos. No conjunto, houve um total de II\% (14) de trabaIhos envolvendo esse tema.

As teses assim identificadas foram as de BiascoviAssis (1997), Paula (2000) e Yano (2003), e as dissertações foram de Souza (s/d), Silva (1992), Chacon (1995), Franco (1998), Marques (2000), Queiroz (2000), Jordão (200I), Góes (2004), Valle (2004), Nunes (2006) e Turini (2006).

Por hipótese, pode-se dizer que o tema interações sociais tornou-se candente nas pesquisas, em decorrência da demanda gerada na sociedade para inserir as pessoas com deficiência mental em diversos contextos. Nesse sentido, surgiram críticas sobre as práticas excludentes das redes de assistência em instituições asilares bem como em instituições especiais, escolas especiais e outras dessa natureza. $O$ debate sobre $\circ$ local mais adequado para se ensinar pessoas com deficiência mental ainda permaneceu como ponto de conflito e, portanto, merece maiores aprofundamentos.

Denomina-se saúde ao conjunto das produções que estudaram aspectos etiológicos e intervenções terapêuticas das diversas áreas da Saúde junto à pessoa com deficiência mental. II\% (14) dos trabalhos produzidos na área da Saúde trataram de aspectos etiológicos e farmacológicos da deficiência mental. Além disso, destacam-se as pesquisas relacionadas aos processos de intervenções terapêuticas, ligadas à área da Psicologia.

Pode-se considerar, por hipótese, que essas iniciativas devem-se à expansão da Pós-Graduação stricto sensu nas diferentes áreas do conhecimento bem como podem expressar o esforço dos pesquisadores brasileiros em contribuir nessa direção. As teses encontradas foram: Ciampone (1993), Oliver (1998), Fridman (1999), Silveira (2002) e Santos (2002). As dissertações com a mesma temática foram: Yoshico (1994), Cavalcante (1997), Barros (1998), Paiva (1998), Kulik (1999), Costa (2000), Puglia (200I), Carbone (2003) e Marra (2005). 
Deve-se enfatizar, como Bueno (2006, p.I2), que são necessários maiores investimentos da pesquisa sobre a relação saúde-educação, sendo esse eixo fundamental para o êxito das políticas escolares voltadas aos alunos deficientes. $O$ avanço de estudos nessa direção poderia implicar em melhoria das condições de vida da população em pauta. No entanto, vale registrar que são temas de trabalho que têm crescido nas pesquisas acadêmicas.

Os trabalhos que estudaram os processos de inserção dos estudantes com deficiência mental nos diferentes setores da sociedade foram identificados com - tema inclusão. A partir de 1990, as produções acadêmicas da Pós-Graduação que estudavam a integração das pessoas com deficiência faziam críticas aos conceitos e ao modelo médico dos diagnósticos que ainda pairavam sobre as práticas denominadas especiais. A partir de 1997, intensificaram-se os trabalhos com a temática inclusão, embora essa leitura já fosse alvo de debates na Europa, conforme expresso na Declaração de Salamanca (1994).

Os debates sobre a exclusão social são recorrentes a partir daquele período, coincidindo com a mudança da legislação brasileira para a educação, com a promulgação da Constituição Federal de 1988. Temse, por exemplo, a implementação da Política Nacional de Educação Especial (1994) e a Lei de Diretrizes e Bases da Educação Nacional - lei nº 9.394/1996. Dentre os direitos assegurados oficialmente, está o direito à educação para todas as pessoas, indistintamente.

Houve um acúmulo de produções, no período de 1999 a 2005, direcionadas para o tema inclusão de pessoas com deficiência mental. Registra-se II\% (I3) de teses e de dissertações tratando da temática, sendo maior o número de dissertações que se dedicou a pesquisar as diferentes formas de inserção dos estudantes com deficiência na escola, no trabalho e na saúde. Pode-se pesquisar, também, a tese de Souza (2006) e as dissertações de Xavier (s/d), Julia (1997), Bussab (1999), Almeida (1999), Silva (200I), Lima (200I), Tonini (200I), Saad (2002), Pamplim (2005), Sanches (2005), Tannous (2005) e Vieira (2006).

A tese, produzida no período, problematizou a inclusão escolar no atual contexto do sistema de ensi- no (cf. Souza, 2006). O trabalho foi realizado no Programa de Pós-Graduação em Lingüística Aplicada ao Ensino de Línguas da PUC/SP, o que pode ser um indicador da preocupação de outras áreas com o ensino de pessoas com deficiência.

O tema inclusão, no conjunto das produções pesquisadas, foi utilizado para expressar a necessidade de garantir Educação para Todos como sendo um paradigma diferente da integração e que teve como marco fundamental a Declaração de Salamanca (1994). Esta reuniu um conjunto de declarações das Nações Unidas, que estabeleceu regras e padrões sobre a equalização de oportunidades educacionais para todas as pessoas que apresentam necessidades especiais.

$\mathrm{Na}$ compreensão de Bueno (2006), compartilhada pelas pesquisadoras, o referido documento expressa a necessidade de revisão das políticas sociais em face da falência do Estado de direito, sobretudo em países de terceiro mundo onde o fracasso escolar foi e ainda é expressivo. Nesse sentido, faz-se mister a modificação tanto das políticas quanto das práticas educacionais assentadas na perspectiva da homogeneidade.

Foi registrado crescimento no número de matrículas no período de 2000 a 2004 na rede pública nacional em relação à rede privada. Em 2004, 29l.544 estudantes, com deficiência mental em idade escolar, foram matriculados no sistema de ensino brasileiro. No que se refere ao número total das matrículas realizadas nas escolas brasileiras (especial e comum), a SEESP/ME registrou, em 2005, 640.317 alunos que apresentavam necessidades educacionais especiais. As matrículas de pessoas com deficiência mental em idade escolar representaram $43,4 \%$ desse grupo.

No que concernente às pessoas com deficiências mentais severas, não foi encontrada nenhuma referência nos documentos oficiais, assim como não há informações sobre o êxito ou fracasso desses alunos. Esses aspectos merecem pesquisas, sobretudo para que se questione o tipo de educação que tem se efetivado nas perspectivas das atuais políticas públicas brasileiras.

Classifica-se como avaliação educacional as produções que analisaram os elementos pessoais, sociais e institucionais e os métodos empregados para aferi- 
ção do processo de ensino e aprendizagem, controle de disciplinas, expectativas do corpo discente, docente e familiar. Os pesquisadores que trataram de temas relacionados à avaliação educacional fizeramno com o objetivo de problematizar as práticas de avaliação das diferentes formas de aprendizagem. Esse assunto foi relacionado ao processo de ensino, bem como ao projeto político pedagógico da escola, apontando para as dificuldades de se encontrar métodos de avaliação que ofereçam indicadores sobre a aprendizagem das pessoas com deficiência mental.

Nessa direção, destaca-se o interesse dos pesquisadores em estudar os processos de avaliação educacional empregados pelos professores de estudantes com deficiência mental. Utilizando os Sistemas de Avaliação de Habilidades Sociais elaborados por Gresham e Elliott (1990) e pelo sistema Raven, RosinPinola (2006) comparou os resultados de dois grupos diferentes, os de baixo rendimento acadêmico com deficiência mental e o outro de alto rendimento acadêmico, sem deficiência mental, matriculados no ensino comum. Nessa perspectiva, houve uma diferenciação no que se refere aos resultados apresentados nos itens de habilidades sociais, rendimentos acadêmicos e problemas de comportamento.

Tafla (1994), Rodrigues (1998), Campelini (2004), Hansel (2003), Angélico (2004), Souza (2005) e Schutz (2006) também investiram nessa direção, porém, com orientações diversas, destacando-se a construção de um sistema de avaliação que visa ao acompanhamento do processo de ensino-aprendizagem, envolvendo o aluno, o professor e o contexto escolar. Esse viés pretende superar $\circ$ entendimento de avaliação restrito à verificação sistemática da prática educativa em relação aos conteúdos e aos objetivos previstos, o que faz prevalecer, ainda, uma avaliação de caráter somativo. Essa perspectiva exige um marco de referências que avance os ditames do currículo cognitivista, que se assenta no critério da homogeneização das classes escolares, impondo um tipo de inclusão que favorece a desigualdade social.

Há um esforço da academia em quebrar idéias préestabelecidas sobre a deficiência entendida como problema e não como um desafio a ser enfrentado. Isso tem permitido aos envolvidos, possibilidades de cons- trução de formas de comunicação com as pessoas deficientes (cf. Tunes, 2003).

As teses e as dissertações que problematizaram o conceito de deficiência mental foram agrupadas sob o tema concepção de deficiência mental. As diferentes formas de conceber a deficiência mental e suas implicações para o processo educacional foram objeto de análise de $7 \%$ dos trabalhos encontrados, o que pode ser considerado um dos indicadores de que os pesquisadores brasileiros esforçam-se em quebrar as crenças e os mitos que pairam sobre as pessoas com deficiência mental. Foram classificadas com essa temática as teses de Mendes (1995), Marques (2000), Camargo (2000) e Oliveira (2002), e as dissertações de Ghur (1992), Ferreira (1997), Kalmus (2000) e Holanda (2000).

A compreensão de deficiência mental adotada no interior das instituições especiais, que a vincularam a uma condição de incapacidade mediante as exigências cognitivas, emocionais e sociais das demandas do processo de desenvolvimento, foi objeto de críticas, o que coincidiu com as tendências das produções acadêmicas encaminhadas nestes últimos 15 anos. Nesse sentido, os diagnósticos da deficiência mental não atenderam de forma integral aos critérios mínimos estabelecidos pela Associação Americana de Retardo Mental, versão de 1973. E tal situação, até a presente data, ainda é uma realidade (cf. Anache, 2006).

Sob o tema aprendizagem, reuniu-se um conjunto de teses e de dissertações que pesquisou as formas de aprender dos estudantes com deficiência mental, envolvendo aspectos cognitivos, afetivos, motricidade, personalidade e criatividade, ou seja, considerando-o como uma ação singular do sujeito que aprende. Com essa temática, foram encontrados $6 \%$ (7) entre o total de 122 trabalhos pesquisados.

Luz (1999) analisou as condições e as possibilidades de abstração em jovens com deficiência mental, tendo por base o referencial histórico-cultural, e argumentou que a abstração, como modo de funcionamento mental, é uma elaboração coletiva e histórica e não uma pré-condição para que essas pessoas sejam incluídas nas práticas sociais. Portanto, há que se indagar sobre a efetividade das atividades propostas aos estudantes, que dissociam a teoria da prática, ou ainda, o abstrato do concreto. 
Tijiboy (200I) estudou o modo como as pessoas com paralisia cerebral apropriam-se dos recursos tecnológicos de um ambiente computacional telemático e que processos de desenvolvimento ocorrem quando se valem desses recursos. Porém, não há alusão no resumo se os dois estudantes de 20 anos que freqüentavam o Núcleo de Informática na Educação Especial da Universidade Federal do Rio Grande do Sul eram deficientes mentais. Vale registrar que a paralisia cerebral nem sempre está associada à deficiência mental.

Oliveira (2002) investigou o papel da familiaridade dos estímulos na emergência de equivalência em pessoas surdas e com deficiência mental. A estratégia experimental consistiu em ensinar oito alunos, com idade variando entre 8 e 26 anos, utilizando duas relações condicionais, envolvendo os conjuntos de estímulos familiares e abstratos, seguidas pelos testes das relações emergentes de equivalência. A relevância desse estudo está na investigação de procedimentos de ensino que possibilitem a aprendizagem de pessoas com dupla deficiência.

Rubim (2003) analisou o desempenho de jovens e adultos na faixa etária de 16 a 23 anos, com deficiência mental moderada, no processo de aprendizagem da leitura, da escrita e da Matemática, relacionado aos conteúdos das séries iniciais do Ensino Fundamental. A pesquisadora constatou que, ao receberem programas de intervenção que consideram a idade cronológica, seus interesses e suas necessidades individuais, as pessoas demonstraram potencial para a aquisição de conceitos pertinentes às áreas mencionadas.

O trabalho produzido por Piccolo (2004), cujo resumo foi fiel ao título da tese, Aprendizagem observacional, formação e expansão de classes de equivalência, refere-se à aprendizagem observacional e à expansão de classe de equivalência por meio do uso de software de pesquisa de Spell. Visou-se à observação de como as classes de equivalência estabelecidas com base em discriminações condicionais aprendidas por observação podem ser ampliadas por meio de estímulos associados a outras/novas discriminações condicionais aprendidas pelas observações.

Carvalho (2004) realizou sua pesquisa, no interior de uma escola especial, com jovens adultos que apre- sentavam deficiência mental, visando analisar a relação que eles estabelecem com o conhecimento e a importância das práticas educativas implicadas no processo de seu desenvolvimento. A pesquisadora apresentou as dificuldades enfrentadas pelos estudantes, mediante as contradições vividas no processo de escolarização.

Os trabalhos que analisaram os cursos de formação de profissionais para atuação junto às pessoas com deficiência mental foram agrupados sob o tema formação profissional, perfazendo um total de $5 \%$ das produções acadêmicas recolhidas. Dechichi (200I), por exemplo, investiu na transformação do ambiente da sala de aula em um contexto promotor de desenvolvimento a partir das mudanças na relação professor-aluno. Com base em um referencial ecológico, a autora defendeu a necessidade de revisão da atuação bem como da formação do professor. Nessa mesma direção, Weiss (2003) propôs analisar o processo de formação em serviço de professores de estudantes com deficiência mental e, por meio dos recursos oferecidos pela Informática à Educação Especial, desenvolveu estratégias metodológicas para promover o desenvolvimento de uma postura reflexiva e crítica dos professores.

Os resumos das produções indicaram que essas discussões fomentaram o debate entre os pesquisadores que se dedicam a estudar a formação de profissionais que atuam junto às pessoas com deficiência, pois, na perspectiva da inclusão, há que se pensar em uma outra configuração para o profissional das diferentes áreas do conhecimento. Alternativas educacionais que minimizem os efeitos da deficiência para o sujeito requerem dos profissionais orientações teóricas e metodológicas que ofereçam oportunidades de aprendizagem a todos os alunos.

As produções que tiveram como objeto de estudo as intervenções construídas no âmbito da instituição escolar e que privilegiaram as diferentes formas de comunicação e de expressão ocorridas entre os professores(as) e os estudantes, classificam-se como ensino-aprendizagem. Essa relação foi tema de $4 \%$ das pesquisas desenvolvidas. A incidência desse tema expressa, por um lado, certo otimismo por parte dos pesquisadores sobre as possibilidades de aprendiza- 
gem das pessoas com deficiência mental. Contudo, por outro, também indicam as dificuldades que as instituições escolares possuem na promoção do ensino às pessoas com deficiência mental.

Almeida (1993) pesquisou a construção da lectoescrita em estudantes com deficiência mental, tratando dos determinantes da deficiência mental em interação na sala de aula e na comunidade onde vivem. No entanto, o resumo desse estudo não está disponível no Portal da CAPES. Com esse mesmo objeto, temos o trabalho de Melo (2004), tendo por base a teoria da Modificabilidade Cognitiva de Feuerstein, ressaltando a importância da interação no processo de aquisição da leitura e da escrita.

Ferreira (1994) analisou um conjunto de informações obtidas por intermédio de professores, de mães e de alunos com deficiência mental de uma instituição especializada, por meio da abordagem denominada pela autora de sociocultural, a partir da Teoria da Atividade proposta por Leontiev. Seu trabalho evidenciou que na prática educacional predomina $\circ$ treino de habilidades básicas, restringindo-se as possibilidades de apropriação de formas culturais da atividade humana, havendo respaldo em concepções de desenvolvimento reduzidas a um somatório de aprendizagens, mesclado com uma visão inatista.

Ainda nessa perspectiva, por meio do paradigma indiciário proposto por Ginzbug (1990)², Padilha (200I) construiu estratégias metodológicas de intervenção com Bianca, uma jovem de 17 anos que apresentava agenesia do corpo caloso e seu hemisfério esquerdo bastante diminuído em relação ao tamanho do direito. Segundo a avaliação clínica institucional, a jovem apresentava dificuldades sensoriais, motoras, verbal e cognitiva, o que lhe conferia o diagnóstico de deficiência mental.

Tavares Silva (2003) pesquisou as relações de ensino e aprendizagem estabelecidas no interior das salas de recursos a partir de uma análise sociológica. A autora problematizou o currículo cognitivista presente no locus de seu estudo. A dissertação de Solér (200I) enfocou o processo de alfabetização e suas relações com a construção do conhecimento em uma perspectiva construtivista. As duas produções supra- citadas, mesmo sendo de orientações teóricas diferentes, trazem em comum críticas ao modelo atual de ensino das escolas brasileiras bem como ao tipo de inclusão educacional oferecido por elas.

As pesquisas realizadas por Nunes e cols. (1998) recomendam a continuidade dos estudos sobre 0 processo de ensino-aprendizagem, uma vez que esse é tratado de forma descontínua, abrangendo vários assuntos, dentre eles, procedimentos e processos de aprendizagem de habilidades acadêmicas, sociais, esportivas, artísticas e de comunicações e auto-cuidados. Segundo as pesquisadoras, os aspectos emocionais e afetivos do portador de necessidades especiais são pouco contemplados se comparados à relevância atribuída aos aspectos cognitivos.

As produções que enfocaram o impacto dos programas dos cursos oferecidos para os estudantes com deficiência mental no interior das instituições (especiais ou não) foram identificadas com o tema formação para o trabalho, perfazendo um total de $5 \%$ dos trabalhos pesquisados.

Lucena (1998) e Silva (2000) propuseram-se estudar os programas de educação profissional oferecidos por uma instituição especializada e de que modo eles se situavam mediante a realidade econômica e política de seus países (Brasil e Espanha). Os autores entrevistaram pessoas com deficiência e, entre elas, aquelas que apresentavam deficiência mental, com o objetivo de analisar a efetividade dos programas de reabilitação profissional para a sua inserção no mercado de trabalho. Giordano (1994) deu voz aos trabalhadores com deficiência mental e estudou as representações que eles possuem sobre 0 trabalho.

As produções que se voltaram para temas relacionados à sexualidade de pessoas com deficiência mental como um atributo que se constitui no processo de desenvolvimento compreendeu três aspectos intercambiantes: o biológico, a socialização e o psicoemocional. Trata-se do papel sexual construído pela pessoa para viver as suas relações sociais e interpessoais. Computou-se $2 \%$ das pesquisas em foco estudando esse tema.

Melo (2004) realizou uma pesquisa-intervenção junto aos professores do Ensino Fundamental que atuam com estudantes que apresentam deficiência 
mental, e Amaral (2004) estudou a efetividade do programa de orientação sexual para pessoas com deficiência mental. Ambas as pesquisas alertam para a necessidade de se manter, construir e implementar trabalhos dessa natureza uma vez que esse é um campo ainda pouco referenciado nas pesquisas.

As pesquisas sobre as tecnologias da informação e da comunicação foram aquelas que trataram dos recursos da Informática como possibilidade para a promoção do desenvolvimento de habilidades das pessoas com deficiência mental. $2 \%$ dos trabalhos voltam-se para esse tema.

Franco (2002) analisou os recursos oferecidos pela Informática no processo de alfabetização de crianças de 8 a 12 anos com necessidades educativas especiais. A autora não esclarece no resumo se essa população é de estudantes com deficiência mental. Carrer (2005) avaliou a tecnologia de reconhecimento de fala, juntamente com software mestre, para verificar se há viabilidade de utilizá-lo para fins educacionais. $\mathrm{O}$ autor analisou 110 crianças com deficiência mental e transtornos fonológicos na faixa etária de 4 a II anos, concluindo que o referido recurso constitui-se em instrumento de auxílio para facilitar o processo de identificação da linguagem nas séries iniciais do Ensino Fundamental.

As produções que tiveram como objetivo estudar os processos de desenvolvimento da pessoa com deficiência mental em uma perspectiva histórico-cultural foram identificadas como constituição do sujeito e analisou a significação do social nesse processo. Kassar (200I) apresentou a trama na qual a história social tem se manifestado na interpretação dos discursos, dos gestos e nas diferentes formas de expressões e de participações nas atividades cotidianas de oito jovens com idade variando entre 13 e 25 anos.

Trabalhos que trataram das políticas públicas de atendimento à pessoa com deficiência mental, sobretudo àquelas que são mais comprometidas, foram registrados. Essa lacuna é também identificada nas legislações brasileiras atuais conforme foi evidenciado por Kassar (200I). Em que pesem as legislações oficiais que versam sobre a garantia de ensino a todos, há indícios de que as dificuldades são gestadas no interior de uma cultura acadêmica que não incluiu em seu projeto pedagógico $\mathrm{o}$ atendimento ao deficiente mental.
O crescimento das produções acadêmicas que tratam de temas relacionados à educação e à saúde de estudantes com deficiência mental não esgotam as indagações sobre as possibilidades de aprendizagem dessas pessoas. Isso exige dos pesquisadores, contribuições para a descoberta das especificidades implicadas nesse tipo de deficiência. Assim, entendese ser necessário analisar a tendência teóricometodológica apresentada nos resumos dos trabalhos pesquisados.

\section{Marcos teóricos e metodológicos das pro- duções acadêmicas}

Os resumos das produções acadêmicas, até a presente data, ofereceram possibilidades de identificação das bases teóricas e metodológicas em que eles se assentam. Registra-se que $27 \%$ deles não continham informações a respeito desse aspecto e $30 \%$ dos trabalhos não disponibilizaram os seus resumos na Base de Dados da CAPES. Contudo, isso não invalidou as reflexões que foram extraídas da ausência, da pertinência ou mesmo da impertinência de algumas delas, determinantes na construção da informação.

O referencial teórico-metodológico é de grande valia para a construção de um trabalho científico, pois ele orienta o caminho do pesquisador. Assim, dependendo da concepção de sujeito, de ciência, de deficiência, de educação e de aprendizagem, o autor posiciona-se. Há uma "lente" escolhida para tal empreendimento. Ainda que $\circ$ pesquisador busque a impessoalidade ou a neutralidade preconizada pela ciência positivista, elas também têm suas marcas, portanto, sua ideologia. A teoria não é um sistema estático, mas um sistema aberto que possibilita a interlocução com os momentos empíricos do processo. É necessário, porém, um marco teórico estabelecido.

Nos $43 \%$ (53) trabalhos que disponibilizaram os seus resumos e informaram a abordagem teórica eleita, observou-se a diversificação dos aportes. Destacou-se o sócio-histórico, ou seja, as produções que definiram os seus aportes como sendo embasados nos princípios de Vygotsky (1997), com 32\% do total informado, e a perspectiva comportamental, mencionada em $23 \%$ do conjunto das produções. 
Há predomínio do aporte da ciência positivista nos trabalhos, com o seu discurso de vanguarda e com a promessa de modernização do sistema de ensino por meio de tecnologias. Ao retomarem-se as críticas ao sistema educacional brasileiro, a partir de meados de 1980, as idéias de Vygotsky tiveram boa acolhida nesse cenário, mesmo com interpretações que separavam o referido autor de sua base teórica original, ou seja, o materialismo histórico, como discutem Gonzalez Rey (2005) e Duarte (1999). Segundo os autores, há a tendência em separar Vigotsky do marxismo e do contexto da Psicologia soviética como um fenômeno mundial, vigente por onde a ideologia neoliberal e pós-moderna tem se propagado.

A interpretação do pensamento de Vigotsky pode ser realizada de diversas formas, dentre elas, associando-o a outras teorias que não se coadunam com o universo filosófico marxista. Como exemplo disso, tem-se a sua associação à obra de Jean Piaget. $\mathrm{Na}$ educação e, sobretudo, na Educação Especial, a junção entre os dois pensadores tem se apresentado como alternativa para os problemas educacionais.

No conjunto das produções, foram detectadas outras abordagens, entre elas, a psicanalítica, a psicogenética e a ecológica. Ainda que inexpressivas em números, elas anunciam outras possibilidades de estudo da educação de pessoas com deficiência mental. Diante disso, entende-se ser pertinente identificar o foco dos estudos que se propuseram pesquisar a educação de pessoas que apresentam deficiência mental.

No universo de $64 \%$ (78) trabalhos que informaram a população alvo de suas teses e dissertações, $56 \%$ (44) deles citaram como sujeito de suas pesquisas 0 estudante com deficiência mental, 16\% (12) trataram dos professores e I3\% (10), das famílias. Em uma análise mais profunda, observou-se que houve um esforço na análise dos processos pedagógicos, expressados em pesquisas sobre as intervenções junto aos estudantes e aos professores. Esse é um indício da preocupação em construir estratégias de ensino apropriadas para proporcionar aprendizagem e/ou como construção de recursos técnicos a fim de avaliar e diagnosticar a deficiência do grupo em destaque.
A título de ilustração, na dissertação de Valle (2004), entrevistaram-se jovens adultos com deficiência mental com o intuito de identificar em seus relatos pessoais fatos que tenham contribuído para sua inserção no mercado de trabalho. Rubim (2003) estudou o desempenho acadêmico em Língua Portuguesa e em Matemática de sete jovens adultos com deficiência mental. A dissertação de Hansel (2003) estudou as principais dificuldades que oito professores e 16 alunos encontraram no processo de avaliação mediadora. Piccolo (2004) realizou pesquisa experimental com sujeitos que apresentavam deficiência mental. Outras pesquisas também se destacaram ao dar voz à pessoa com deficiência mental, dentre elas, as realizadas por Padilha (1994 e 200I), Kassar (200I) e Carvalho (2004). Esses trabalhos valeram-se de técnicas de pesquisas citadas nos resumos, com destaque para as entrevistas, os estudos de casos, os experimentos e as observações.

Num conjunto de $55 \%$ do universo de 122 trabaIhos pesquisados, 67 disponibilizaram os instrumentos empregados nas produções; as entrevistas foram consideradas os prediletos dos autores, com 19\% (13) do conjunto. Em seguida, está a pesquisa experimental 16\% (II), depois a observação 12\% (8) e, finalmente, os estudos de casos $12 \%$ (8), havendo também a conjugação de entrevistas e observações em 9\% (6), cumprindo a tradição de trabalhos dessa natureza realizados pelas áreas da Educação e da Psicologia. Vale salientar a presença de alternativas de pesquisas, como a pesquisa-ação, em $9 \%$ (6) dos trabalhos, salutar, uma vez que isso pode ser um indicativo das possibilidades de obtenção de informações sobre uma população que se expressa pela incapacidade de se adaptar às normas vigentes na sociedade. Entretanto, esse é um aspecto que merece aprofundamentos, extrapolando os limites deste estudo.

\section{Considerações Finais}

O levantamento das pesquisas acadêmicas sobre a deficiência mental possibilitou compreender o lugar 
que nela ocupam os trabalhos direcionados ao processo de aprendizagem da população com deficiência mental. Considerou-se que esse é um tema inquietante tanto para os pesquisadores quanto para os profissionais que atuam diretamente com as pessoas que apresentam essa deficiência.

Vale ressaltar que este tipo de pesquisa demonstrou a necessidade de aprimoramento dos bancos e das bases de dados que registram as produções realizadas pela academia uma vez que vários trabalhos foram encontrados que poderiam ser analisados por meio de seus resumos e de seus textos na íntegra se eles estivessem disponibilizados na Base de Dados do Portal da CAPES. Um outro aspecto relevante diz respeito aos descritores referentes às teses e às dissertações catalogadas no Banco de Dados. Eles nem sempre coincidem com o conteúdo tratado nas produções às quais teve-se acesso. Desse modo, os pesquisadores deveriam dar maior atenção à escolha das palavras-chaves que identificam o trabalho.

Com relação aos temas tratados no conjunto das produções acadêmicas, observou-se que as estratégias de avaliação e de diagnóstico bem como as questões relacionadas ao processo de ensino, às interações sociais, à saúde, à inclusão e à avaliação educacional sugerem, em uma primeira análise, que o tema aprendizagem foi pouco contemplado $6 \%$ (7). No entanto, todos os temas estão relacionados, ainda que indiretamente, à necessidade de construção de estratégias para a compreensão do processo de aprendizagem e de desenvolvimento da pessoa com deficiência mental. Essa hipótese se pauta na compreensão de que a aprendizagem não se refere ao domínio cognitivo. Ela é, sim, um processo no qual participam, de diversas formas, a subjetividade das pessoas com deficiência mental. Portanto, essas relações precisam conhecer um tratamento menos reducionista por parte dos estudiosos.

A aprendizagem é um processo partilhado e relacional que ocorre nas condições concretas de vida das pessoas, possibilitando a constituição dos sistemas funcionais cerebrais. $O$ desenvolvimento psicológico resulta da síntese entre os aspectos biológicos e psicossociais, admitindo a plasticidade cerebral, o que implica em transformações dos sujeitos envolvi- dos, por meio das suas diferentes formas de relações sociais.

Percebeu-se $o$ aumento de trabalhos que se respaldam na perspectiva sócio-histórica como possibilidade de romper com a visão ambientalista de educação, de sujeito e de deficiência, tradicional na educação de pessoas com deficiência mental. As críticas se referem à redução do processo educativo a uma lista de objetivos a serem atingidos. Desse modo, elimina-se a função do sujeito que aprende e, conseqüentemente, limita-se o ensino ao preparo de competências para adaptação às atividades humanas.

Com base na perspectiva sócio-histórica, Luz (1999) e Carvalho (2004) criticaram as práticas educacionais realizadas no interior das instituições pesquisadas, que se orientavam na compreensão de que o desenvolvimento é um conjunto de aprendizagens que a pessoa adquire de forma linear e cumulativa, portanto, aprendizagem e desenvolvimento são entendidos como processos coincidentes. As autoras observaram que as práticas educativas são possibilidades de ampliação da participação social.

A partir dessa percepção, desenvolveram-se proposições sobre a necessidade de um outro modelo educacional, capaz de possibilitar à pessoa com deficiência mental, com suas diferenças de desenvolvimento, a inserção na escola, no trabalho e em outros segmentos da sociedade (cf. Carvalho, 2004).

Luz (1999, p. I19) afirma que o processo de abstração, necessário para o processo de formação de conceitos, portanto, uma categoria relacional e histórica, não pode deixar de ser considerado como "[...] pensamento hierárquico, categorial e único. Não mais como a única possibilidade de participação e "humanização"'.

Rubim (2003) realizou sua pesquisa fundamentada em uma perspectiva ecológica, que compreende o currículo funcional como alternativo de programas de ensino especial. Conforme já mencionada neste artigo, a autora realizou uma avaliação inicial e processual do desempenho de jovens e adultos com deficiência mental quanto à aquisição de conteúdos de Língua Portuguesa e Matemática. Desse modo, a deficiência mental é considerada uma condição desarmônica entre o indivíduo e o ambiente no qual ele funciona. Tanto as características do próprio sujeito como os com- 
ponentes ambientais que o circundam poderão impor limitações sobre o seu funcionamento e sua adaptação presente. A avaliação consiste em identificar a capacidade de adaptação das pessoas com deficiência mental, requerendo as habilidades para atuar nos ambientes dos quais ela participa. $O$ ensino visa proporcionar a aprendizagem dos sujeitos sempre em situação real ou natural. As habilidades devem ser funcionais, visando aumentar a independência do sujeito em um determinado ambiente e tornando seu comportamento (global e não específico) o mais próximo possível do comportamento de outras pessoas naquela mesma situação.

Sob essa orientação, Rubim (2003) constatou que os estudantes participantes da pesquisa apresentaram evolução significativa nos conteúdos de Língua Portuguesa e Matemática, relacionados às séries iniciais do Ensino Fundamental, o que lhe permitiu afirmar que essas pessoas apresentavam potencial para a aquisição de conceitos necessários para alfabetização, desde que os programas de ensino fossem adequados às suas características individuais.

Piccolo (2004) entendeu que investigar na área de equivalência de estímulos facilita a construção de estratégias de ensino que podem ser manipuladas, visando à eficiência da aprendizagem de discriminações condicionais e a formação de classes de equivalência, sobretudo na aprendizagem de pessoas com necessidades especiais. Essa terminologia foi empregada pela autora para se referir aos estudantes que apresentavam deficiência mental. Nesse enfoque, a aprendizagem por observação pode acelerar o processo de aprendizagem de novos comportamentos que são aprendidos por meio de modelos, uma vez que eles fornecem uma demonstração da resposta a ser emitida. Na compreensão de autores da linha comportamental, a imitação é um processo vinculado a esse tipo de aprendizagem.

Esse tipo de abordagem pode ser viável para o ensino de diferentes populações. Entretanto, Piccolo (2004) alerta para a necessidade de mais pesquisas com estudantes com necessidades educacionais especiais. $O$ uso de alternativas metodológicas para a aprendizagem dessas pessoas evidencia as suas possibilidades de desenvolvimento cognitivo. $O$ esforço deverá ser para realizar um planejamento que acompanhe o ritmo do estudante, o que requer uma avaliação rigorosa do comportamento dessa pessoa.

O conjunto das produções analisadas, embora com aportes teóricos e metodológicos diferentes, mostrou o investimento dos pesquisadores no aprimoramento de conhecimentos sobre diversos aspectos que expressam direta ou indiretamente a crença nas possibilidades de desenvolvimento das pessoas com deficiência mental. Acredita-se que ainda há muito que pesquisar sobre os processos de aprendizagem de pessoas com deficiência mental. Contudo, as informações obtidas até o presente momento oferecem subsídios para a reflexão sobre o tipo de compromisso que se assume com nossas produções acadêmicas.

Concluí-se, enfim, que ainda há escassez de pesquisas na área, alertando para a necessidade de realização de estudos sobre os processos de aprendizagem de pessoas com deficiência mental, sobretudo daquelas consideradas mais comprometidas, capazes de oferecer subsídios para possibilitar o seu desenvolvimento.

\section{Referências}

Almeida, D. B de. (1999). Do especial ao inclusivo? Um estudo da proposta de inclusão escolar da rede estadual de Goiás, no município de Goiânia. Dissertação de Mestrado, Universidade Estadual de Campinas, Campinas, SP.

Almeida, R. (1972). Avaliação das teses de mestrado na área de educação no Estado do Rio de Janeiro. Dissertação de Mestrado, Universidade Federal do Rio de Janeiro, Rio de Janeiro, Rio de Janeiro.

Almeida, R. A. (1993). Deficiência mental e construção da lectoescrita: determinantes da deficiência mental de alunos de classe especial em interação na sala de aula e na comunidade em que vivem. Dissertação de Mestrado, Universidade Federal do Rio Grande do Sul, Porto Alegre, Rio Grande do Sul.

Amaral, M. C. (2004). Sexualidade e deficiência mental: um impacto de um programa de orientação para famílias. Dissertação de Mestrado, Universidade Federal de São Carlos, São Carlos, São Paulo. 
American Psychiatric Association. (1995). D.S.M.- IV-TM - R. Manual de Diagnóstico e Estatística de Distúrbios Mentais. (D. Batista, trad.). Porto Alegre: Artes Médicas. (Trabalho original publicado em 1994).

Anache, A. A. (1997). Diagnóstico ou inquisição? Estudo sobre o uso do diagnóstico psicológico na escola. Tese de Doutorado, Universidade de São Paulo, São Paulo, São Paulo.

Anache, A. A. (2006) Estudo sobre o processo de institucionalização de alunos que apresentam deficiência mental severa. Em: Neres, C. C. e Pulchério, S. S. L. Educação Especial em Foco. Campo Grande: Universidade Para o Desenvolvimento da Região do Pantanal - UNIDERP. (p. I33-I50).

Anache, A. A. (2007). A pessoa com deficiência mental entre os muros da educação. Em H. R. Campos (Org.), Formação em Psicologia Escolar: realidades e perspectivas (pp. 23I-244). Campinas: Alínea.

Angélico, A. P. (2004). Estudo descritivo do repertório de habilidades sociais de adolescentes com Síndrome de Down. Dissertação de Mestrado, Universidade Federal de São Carlos, São Carlos, SP.

Barros, J. de F. (1998). Estudo comparativo dos índices de aptidão física em portadores de deficiência mental. Dissertação de Mestrado, Universidade Federal de São Paulo, São Paulo, SP.

Biascovi-Assis, S. M. (1997). Lazer e deficiência mental: o papel da família e da escola em uma proposta de educação pelo e para o lazer. Tese de Doutorado, Universidade Estadual de Campinas, Campinas, SP.

Brasil, Ministério da Educação e Cultura. (1996). Lei de Diretrizes e Bases da Educação Nacional. Brasília, DF: Senado Federal.

Brasil. (1994). Declaração de Salamanca. Conferência Mundial sobre Necessidades Educativas Especiais. Linha de Ação sobre Necessidades Educativas Especiais. Brasília, DF: CORDE.

Brasil. Ministério da Educação e do Desporto. Secretaria de Educação Especial. (1994). Política Nacional de Educação Especial. Brasília, DF: Secretaria de Educação Especial, MEC.

Brasil. Ministério da Educação, INEP, SEEC. Censo Escolar. (2004). Evolução da matrícula de alunos com necessidades especiais por natureza de deficiência. 2000 a 2004. Disponível em: http:// portal.mec.gov.br/seesp/index.php. Recuperado: 7 mai. 2006.

Brasil. Ministério da Educação. Secretaria de Educação Especial. Coordenação Geral de Planejamento. (2006). Números da Educação Especial no Brasil. Brasília-DF. Disponível em: http:/ /portal.mec.gov.br/seesp/index.php. Recuperado: 7 mai. 2006. SEESP/MEC registrou, em 2005.
Bueno, J. G. S. (2002). A Educação Especial nas Universidades Brasileiras. Brasília, DF: Ministério da Educação, Secretaria de Educação Especial.

Bueno, J. G. S. (2006). As políticas de inclusão escolar: uma prerrogativa da educação especial? Em XIII Encontro Nacional de Didática e Prática de Ensino: Educação, questões pedagógicas e processos formativos: compromisso com a inclusão social (p. I14). Recife, PE: ENDIPE.

Bussab, M. B. (1999). Da integração desejável à possível do portador de deficiência mental na classe comum da rede de ensino do Estado de São Paulo. Dissertação de Mestrado, Universidade de São Paulo, São Paulo, SP.

Camargo, E.A. A. (2000). Concepções de deficiência mental por pais e profissionais e a constituição da subjetividade da pessoa deficiente. Tese de Doutorado, Universidade Estadual de Campinas, Campinas, SP.

Campelini, V. L. M. F. (2004). Avaliação das possibilidades do ensino colaborativo no processo de inclusão escolar de alunos com deficiência mental. Dissertação de Mestrado, Universidade Estadual de Campinas, Campinas, SP.

Carbone, P. H. L. (2003). Pesquisa de anticorpos dirigidos a antígenos de fase latente e lítica do herpes vírus humano tipo 8 (HHV-8): prevalência em populações sob risco epidemiológico em população sadia de São Paulo. Dissertação de Mestrado, Universidade de São Paulo, SP.

Carrer, J. H. (2005). Avaliação de um programa informatizado de reconhecimento de fala em indivíduos com deficiência mental e com problemas de linguagem. Dissertação de Mestrado, Universidade Federal de São Carlos, São Carlos, São Paulo.

Carvalho, M. F. (2004). A relação do sujeito com o conhecimento: condições de possibilidades no enfrentamento da deficiência mental. Tese de Doutorado, Universidade Estadual de Campinas, Campinas, São Paulo.

Cavalcante, J. C. G. G. (1997). O fazer fonoaudiológico em instituição para o atendimento a pessoa com deficiência mental: um estudo de caso. Dissertação de Mestrado, Pontifícia Universidade Católica de São Paulo, São Paulo, SP.

Chacon, M. C. M. (1995). A integração social do deficiente mental: um processo que se inicia na/pela família. Dissertação de Mestrado, Universidade Estadual de Campinas, Campinas, SP.

Ciampone, M. H. T. (1993). Assistência institucionalizada para indivíduos portadores deficiência mental: dimensões esquecidas. Tese de Doutorado, Universidade de São Paulo, São Paulo, SP. 
Costa, A. M. (2000). Atividade física e a relação com a qualidade de vida, ansiedade e depressão em pessoas com seqüelas de acidente vascular cerebral isquêmico (AVCI). Dissertação de Mestrado, Universidade Estadual de Campinas, Campinas, SP.

Costa, M. C. V. (1994). Pesquisa em Educação: concepções de ciência, paradigmas teóricos e produção de conhecimentos. Cadernos de Pesquisa, 90, 15-20.

Cunha, L. A. (1979). Os (Des)caminhos da pesquisa na pósgraduação. Em Seminário sobre a Produção Científica nos programas de mestrado em Educação (pp. 3-24). Brasília, DF: CAPES.

Dechichi, C. (200I). Transformando o ambiente da sala de aula em um contexto promotor do desenvolvimento do aluno deficiente mental. Tese de Doutorado, Pontifícia Universidade Católica de São Paulo, São Paulo, São Paulo.

Di Dio, R. A. (1976). A pesquisa educacional no Brasil. Revista Brasileira de Estudos Pedagógicos, 136, 518-526.

Dias, T., Goyos, C., Ferrari, C., Dall'Alba, L., Santos, L., \& Omote, S. ( 1 987). Caracterização da produção científica do Programa de Mestrado em Educação Especial: dissertações de mestrado. Trabalho apresentado no IV Ciclo de Estudos sobre Deficiência Mental. Universidade Federal de São Carlos, São Carlos, São Paulo.

Duarte, N. (1999). Vygotsky e o "aprender a aprender": críticas às apropriações neoliberais e pós-modernas da teoria Vygotskiana. Tese de Livre-Docência, Faculdade de Ciências e Letras, Universidade Estadual Paulista de Araraquara, Araraquara, São Paulo.

Feldens, M. G. F. (1983). Alternativas Metodológicas para a pesquisa em Educação. Ciência e Cultura, 35(10), I2I-I 26.

Ferreira, A. I. de F. (1997). Avaliação motora para a pessoa deficiente mental nas APAEs da região de Campinas - SP: um estudo de caso. Dissertação de Mestrado, Universidade Estadual de Campinas, Campinas, SP.

Ferreira, M. C. C. (1994) A prática educativa e a concepção de desenvolvimento psicológico de alunos com deficiência mental. Tese de Doutorado, Universidade Estadual de Campinas, Campinas, São Paulo.

Franco, A. M. (2002). A informática como recurso pedagógico no processo de alfabetização de crianças como Necessidades Educativas Especiais. Dissertação de Mestrado, Universidade Federal de Santa Catarina, Florianópolis, Santa Cantarina.

Franco, A. R. F. (1998). Encontro afetivo em sala de aula: um estudo com professoras de alunos com deficiência mental. Dissertação de Mestrado, Universidade Estadual de Campinas, Campinas, SP.
Fridman, C. (1999). Os mecanismos genéticos nas síndromes de Prader-willi e Angelman. Tese de Doutorado, Universidade de São Paulo, São Paulo, SP.

Gatti, B. (1983). Pós-graduação e pesquisa em educação no Brasil - 1978-198I. Cadernos de Pesquisa, 44, I3-I7.

Ginzburg, C. (1990) Mitos, emblemas, sinais: Morfologia e história. São Paulo: Companhia das Letras.

Giordano, B. W. (1994). (D)eficiência: uma análise das representações do trabalho e do ser trabalhador com deficiência mental. Dissertação de Mestrado, Pontifícia Universidade Católica de São Paulo, São Paulo, São Paulo.

Goergen, P. L. ( 1981 ). Pesquisa em Educação, sua função crítica. Revista Educação e Sociedade, 9, 65-69.

Góes, F. A. de B. (2004). Os pais e seu filho portador de necessidades especiais - deficiência mental um encontro inesperado. Dissertação de Mestrado, Universidade Católica de Pernambuco, Recife, PE.

González Rey, F. L. (2005). Sujeito e Subjetividade. São Paulo: Thomson.

Gouveia, A. A. (197I). A pesquisa educacional no Brasil. Cadernos de Pesquisa, I(I), I-48.

Gresham, F. M. e Elliott, S. N. ( 1990) Social Skill Rating System: Circle Pines, MS: American Guidance Service. USA.

Guhur, M. de L. P. (1992). Representação da deficiencia mental: esboço de uma abordagem histórica. Dissertação de Mestrado, Universidade Metodista de Piracicaba, Piracicaba, SP.

Hansel, A. J. (2003). Avaliação mediadora: um processo em construção para os professores do ensino fundamental do Centro $\mathrm{Fe}$ deral de Educação tecnológica de São Vicente do Sul. Dissertação de Mestrado, Universidade Federal de Santa Maria, Santa Maria, Rio Grande do Sul.

Hansel, A. J. (2003). Avaliação mediadora: um processo em construção para os professores do ensino fundamental do Centro Federal de Educação tecnológica de São Vicente do Sul. RS. Dissertação de Mestrado, Universidade Federal de Santa Maria, RS.

Holanda, S. A. R. de. (2000). Sobre a questão da deficiência mental concebida como infância eterna: reflexões em direção à psicanálise. Dissertação de Mestrado, Universidade de São Paulo, São Paulo, SP.

Jordão, M. C. M. (200I). A criança, a deficiência e a escola: uma intervenção orientada pela psicanálise. Dissertação de Mestrado, Universidade de São Paulo, São Paulo, SP. 
Júlia, C. H. (1997). A pessoa portadora de deficiência mental em nível educável e o mundo do trabalho: a visão dos empregadores no setor atacadista de Franca. Dissertação de Mestrado, Universidade Estadual Paulista, Marília, SP.

Kalmus, J, (2000). A produção social da deficiência mental leve. Dissertação de Mestrado, Universidade de São Paulo, São Paulo, SP.

Kassar, M. C. M. (200I). Modos de participação e constituição de sujeitos nas práticas sociais: a institucionalização de pessoas com deficiência múltipla. Tese de Doutorado, Universidade Estadual de Campinas, Campinas, São Paulo.

Kulik, S. M. (1999). Estudo descritivo para hepatite B em portadores deficiência de mental e em profissionais de saúde, em uma instituição fechada no Brasil. Dissertação de Mestrado, Universidade de São Paulo, São Paulo, SP.

Lima, A. F. (200 I). Concepção de deficiência mental e da educação inclusiva. Dissertação de Mestrado, Fundação Universidade Estadual do Ceará, Fortaleza, CE.

Lima, P. G. (2003). Tendências paradigmáticas na pesquisa educacional. Artur Nogueira: Amil.

Lucena, N. M. G. (1998). Analisis de un programa de intervencion motriz (expresion corporal como factor de desarollo motor y eficácia laboral em um centro especial de empelo de trabajadores adultos com atraso mental). Tese de Doutorado, Universidad de Granada, Facultad de Ciências de la atividade física y el deporte - Departamento de Educação Física, Granada, Espanha.

Luz, A. O. C. (1999). Será que precisa aprender isso? Um estudo sobre as condições e possibilidades da abstração em jovens com deficiência mental. Dissertação de Mestrado, Universidade Estadual de Campinas, Campinas, São Paulo.

Machado, A. M. (1994). Crianças de Classe Especial - Efeitos do encontro da Saúde com a Educação. São Paulo: Casa do Psicólogo.

Machado, A. M., \& Sousa, M. P. R. (1997). As crianças excluídas da escola: um alerta para a Psicologia. Em P. R. (Orgs.), Psicologia Escolar: em busca de novos rumos. São Paulo: Casa do Psicólogo.

Machado, F. B. T. (2000). Educação ambiental: uma experiência com grupos de adolescentes e adultos portadores de deficiência mental. Dissertação de Mestrado, Universidade de São Paulo, São Paulo, São Paulo.

Manzini, E. J., Paulino, C. V., Corrêa, P. M., Silva M. O., \& Lopes, M. A. C. (2006). Análise de dissertações e teses em educação especial, produzidas no Programa de pós-graduação em Edu- cação da UNESP - Marília (1993-2004). Revista Educação Especial, 28(2), 34I-359.

Maranhe, E. A. (2004). Ensinando categorias estruturais de história a crianças com dificuldades de aprendizagem. Tese de Doutorado, Universidade Federal de São Carlos, São Carlos, São Paulo.

Marques, L. P. (2000). O professor de alunos com deficiência mental: concepção e pratica pedagógica. Tese de Doutorado, Universidade Estadual de Campinas, Campinas, SP.

Marra, R. A. da. (2005). Atendimento psicoterapêutico conjunto pais-crianças em serviço ambulatorial. Dissertação de Mestrado, Universidade Federal de Uberlândia, Uberlândia, MG.

Melo, L. A. A. (2004). De Piaget a Feurstein: um estudo do letramento e da mediação na educação especial. Dissertação de Mestrado, Universidade Federal de Pernambuco, Recife, PE.

Mendes, E. G. (1995). Deficiência mental: a construção científica de um conceito e a realidade educacional. Tese de Doutorado, Universidade de São Paulo, São Paulo, SP.

Nunes, C. C. (2006). Interação entre irmãos de indivíduos com deficiência mental: o papel da idade e do apoio social da família. Dissertação de Mestrado, Universidade Federal de São Carlos, São Carlos, SP.

Nunes, L. R. D. O. P., Glat, R., Ferreira, J. R., \& Mendes, E. G. (1998). Pesquisa em Educação Especial na Pós-Graduação. Rio de Janeiro: Sette Letras.

Nunes, L. R. O. P., Glat, R., Ferreira. J. R., \& Mendes, E. G. (2003). Análise crítica das teses e dissertações sobre educação especial nas áreas de educação e psicologia. Relatório Final de Pesquisa. Processo CNPq.

Oliveira, A. A. (2002). Sampaio de. Representações sociais sobre educação especial e deficiência: o ponto de vista de alunos deficientes e professores especializados. Tese de Doutorado, Universidade Estadual Paulista Julio de Mesquita Filho, Marília, SP.

Oliveira, C. S. (2002). Formação de classes de equivalência com estímulos arbitrários (presumidos familiares e não familiares) em portadores de deficiência mental surdos. Tese de Doutorado, Universidade Federal de São Carlos, São Carlos, SP.

Oliver, F. C. (1998). Saúde mental e saúde da pessoa com deficiência: estudo do processo de incorporação de assistência e dos serviços municipais de saúde numa região do município de São Paulo. Tese de Doutorado, Universidade de São Paulo, São Paulo, SP. 
Padilha, A. M. (1994). Possibilidades de histórias ao contrário ou como desencaminhar o aluno para escola especial. Dissertação de Mestrado, Universidade Estadual de Campinas, Campinas, São Paulo.

Padilha, A. M. L. (200I). Bianca: o ser simbólico: para além dos limites da deficiência mental. Tese de Doutorado, Universidade Estadual de Campinas, Campinas, São Paulo.

Paiva, A. C. de C. (1998). Monitorização terapêutica da teofilina em pacientes portadores de deficiência mental. Dissertação de Mestrado, Universidade de São Paulo, São Paulo, SP.

Pamplim, R. C. de O. (2005). A interface família-escola na inclusão de crianças com necessidades educacionais especiais: uma perspectiva ecológica. Dissertação de Mestrado, Universidade Federal de São Carlos, São Carlos, SP.

Patto, M. H. (199I). A produção do fracasso escolar. São Paulo, Queiroz.

Paula, A. R de. (2000). Asilamento de pessoas com deficiência: Institucionalização da incapacidade social. Tese de Doutorado, Universidade de São Paulo, São Paulo, SP.

Piccolo, A. A. T. (2004). Aprendizagem observacional, formação e expansão de classes de equivalência. Tese de Doutorado, Universidade Federal de São Carlos, São Carlos, São Paulo.

Puglia, P. M. K. (200 I). Porfiria aguda intermitente: estudo clínico de 37 casos. Dissertação de Mestrado, Universidade de São Paulo, São Paulo, SP.

Queiroz, R. M. (2000). A influência da interação entre crianças especiais e crianças normais na construção do conceito de digestão. Dissertação de Mestrado, Universidade Federal de Pernambuco, Recife, PE.

Rodrigues, J. L. (1998). Aspectos de formação e transição em programas para adolescentes e adultos portadores de deficiência mental em instituições especializadas. Dissertação de Mestrado, Universidade Estadual de Campinas, Campinas, SP.

Rosin-Pinola, A. R. (2006). Avaliação de professores sobre o repertório social e acadêmico de alunos com deficiência mental incluídos no ensino regular. Dissertação de Mestrado, Universidade Federal de São Carlos, São Carlos, São Paulo.

Rossit, R. A. S. (2003). Matemática para deficientes mentais: contribuições do paradigma de equivalência de estímulos para o desenvolvimento e avaliação de um currículo. Tese de Doutorado, Universidade Federal de São Carlos, São Carlos, São Paulo.

Rubim, M. H. (2003). Educação de Jovens e Adultos com deficiência mental: análise evolutiva da aprendizagem da língua portuguesa e da matemática. Dissertação de Mestrado, Universidade Federal de São Carlos, São Carlos, São Paulo.

Saad, N. S. (2002). Preparando Caminho para a inclusão: dissolvendo mitos e preconceitos em relação à pessoa com Síndrome de Down. Dissertação de Mestrado, Universidade de São Paulo, São Paulo, SP.

Sanches, A. C. G. (2005). Contextos educacionais e o aluno com necessidade especial [transtorno mental]: um desafio indisciplinar marcado pela dialética exclusão/inclusão. Dissertação de Mestrado, Universidade São Paulo, São Paulo, SP.

Sanches, G. S. A. (1982). Análise epistemológica dos métodos na pesquisa educacional. Dissertação de Mestrado, Universidade de Brasília, Brasília-DF.

Sanches, G. S. A. (1987). Epistemologia da pesquisa em educação: estruturas lógicas e tendências metodológicas. Tese de Doutorado, Universidade Estadual de Campinas, Campinas, São Paulo.

Santos, C. B. (2002). Síndrome do x frágil e retardo mental fraxe: distribuição dos alelos fraxa e fraxe em indivíduos portadores de retardo mental idiopático no Estado do Rio de Janeiro. Tese de Doutorado, Universidade do Estado do Rio de Janeiro, Rio de Janeiro, RJ.

Schütz, M. R. R. dos S. (2006). Avaliação escolar como instrumento de mediação da aprendizagem na educação inclusiva: desafios no cotidiano escolar. Dissertação de Mestrado, Universidade do Vale do Itajaí, Itajaí, RS.

Sella, M. C. (2005). Ensino de discriminações condicionais por imitação: efeitos de dois arranjos de apresentação de tentativas. Dissertação de Mestrado, Universidade Federal de São Carlos, São Carlos, SP.

Silva, A. F. da. (1992). Interações Sociais escolares entre alunos deficientes mentais e alunos normais. Dissertação de Mestrado, Universidade do Estado do Rio de Janeiro, Rio de Janeiro, RJ.

Silva, A. G. (2000). A educação profissional de pessoas com deficiência mental: a história da relação educação especial / trabaIho na APAE-SP. Tese de Doutorado, Universidade Estadual de Campinas, Campinas, São Paulo.

Silva, C. C. B. (2003). O lugar do brinquedo e do jogo nas escolas especiais de educação infantil. Psicologia escolar e do desenvolvimento humano. Tese de Doutorado, Universidade de São Paulo, São Paulo, São Paulo.

Silva, R. da. (200I). O processo de integração da pessoa portadora de deficiência mental no ensino regular municipal de Florianópolis. Dissertação de Mestrado, Universidade Federal do Rio Grande do Sul, Porto Alegre, RS. 
Silva, R. H. R., Vidal, M. H, C., \& Sousa, S. B. (2003). Análise da Temática "deficiência mental" nas dissertações e teses na área de Educação Física e Esportes no Brasil. Reunião Anual da Associação Nacional de Pesquisadores em Educação. Caxambu, MG, 2002. Disponível: www.anped.org.br. Recuperado: 7 jul. 2006.

Silveira, J. O. L. (2002). Manifestações estomatológicas em pacientes portadores de deficiência mental medicados com drogas anticonvulsivantes. Tese de Doutorado, Pontifícia Universidade Católica de São Paulo, São Paulo, SP.

Solér, L. A. F. (200 I). Alfabetização e suas relações com a construção do conhecimento: um estudo em deficiência mental leve. Dissertação de Mestrado, Universidade de São Paulo, São Paulo, São Paulo.

Souza, A. A. (2005). A progressão escolar de alunos com deficiência em classes comuns - a experiência de Santo André. Dissertação de Mestrado, Pontifícia Universidade Católica de São Paulo, São Paulo, SP.

Souza, C. M. (2006). Dilemas da escola inclusiva: Lingüística aplicada ao ensino de línguas. Tese de Doutorado, Pontifícia Universidade Católica de São Paulo, São Paulo, São Paulo.

Souza, L. G. A. de. (2003). Cuidando do filho com deficiência mental: desvelamentos de vivências de pais no ser-com-o-filho. Dissertação de Mestrado, Universidade de São Paulo, Ribeirão Preto, SP.

Tafla, T. R. (1994). Visão lingüística do desempenho ortográfico em crianças normais e crianças portadoras de deficiência mental. Dissertação de Mestrado, Universidade de São Paulo, São Paulo, SP.

Tannous, G. S. (2005). Inclusão de aluno com deficiência mental: experiências psicossociais de professores da escola pública. Dissertação de Mestrado, Universidade Católica Dom Bosco, Campo Grande, MS.

Tavares Silva, F. C. (2003). As relações entre ensino, aprendizagem e deficiência mental desenhando a cultura escolar. Tese de Doutorado, Pontifícia Universidade Católica de São Paulo, São Paulo, São Paulo.

Tijiboy, A. V. (200I). Apropriação das novas tecnologias de informação e comunicação no desenvolvimento de pessoa com paralisia cerebral. Tese de doutorado, Universidade Federal do Rio Grande do Sul, Porto Alegre, Rio Grande do Sul.

Tini, J. R. (2004). Ensino por modelação de discriminações condicionais envolvendo diferentes estruturas de treino e formação de classes de equivalentes. Dissertação de
Mestrado, Universidade Federal de São Carlos, São Carlos, São Paulo.

Tonini, A. (200I). Uma análise do processo de inclusão: uma realidade de uma escola estadual de Santa Maria - RS. Dissertação de Mestrado, Universidade Federal do Rio Grande do Sul, Porto Alegre, RS.

Tunes, E. (2003) Por que falamos de Inclusão? Linhas Críticas, Universidade de Brasília: Brasília, DF, v.9, n. I6, Jan/Jun. Universidade de Brasília.

Turini, F. A. (2006). Comportamentos pró-sociais em crianças com deficiência mental. Dissertação de Mestrado, Universidade Federal do Espírito Santo. Vitória, ES.

Valle, M. H. F. (2004). Vivências de pessoas com deficiência mental inseridas no mercado de trabalho. Dissertação de Mestrado, Universidade do Estado do Rio de Janeiro, Rio de Janeiro, Rio de Janeiro.

Vieira, C. M. (2006). Programa informativo sobre deficiência mental e inclusão: efeitos nas atitudes e concepções de crianças não-deficientes. Dissertação de Mestrado, Universidade Federal de São Carlos, São Carlos, SP.

Vygotsky, L. S. (1997). L. S. Vygotski - Fundamentos de defectología. Madri, Espanha: Visor Dis. S. A.

Warde, M. (1992). A Produção discente dos Programas de Pós-graduação em Educação no Brasil (1982-1991): avaliação e perspectivas. Avaliação e Perspectivas na área de Educação (pp. 5 I-82). Porto Alegre: ANPEd/CNPq.

Weber, S. A. (1992). A Produção recente na área de educação. Cadernos de Pesquisa, 81, 22-32.

Weiss, A. M. L. (2003). A hora e a vez do professor: desafios da formação reflexiva através da informática na educação. Dissertação de Mestrado, Universidade do Estado do Rio de Janeiro, Rio de Janeiro, RJ.

Xavier, E. C. C. (2003). Mais falares de inclusão: diferenças ou repetições. Dissertação de Mestrado, Universidade Estadual de Campinas, Campinas, SP.

Yano, A. M. M. (2003). As práticas de educação em famílias de crianças com paralisia cerebral diplégica espática e com desenvolvimento típico pertencentes a camadas populares da cidade de Salvador. Tese de Doutorado, Universidade de São Paulo, Ribeirão Preto, SP.

Yoshico, T. K. (1994). Pesquisa do sítio frágil no cromossomo $X$ (Fraxa) em pacientes do sexo masculino, portadores de fissura de palato. Dissertação de Mestrado, Instituto de Biociências de Botucatu, Universidade Estadual Paulista. Botucatu, SP. 
Recebido em: 12/03/2007

Revisado em: 02/10/2007

Aprovado em 17/01/2008

Sobre as autoras

Alexandra Ayach Anache (alexandra.anache@hotmail.com) - Professora Doutora do Departamento de Ciências Humanas da Universidade Federal de Mato Grosso do Sul - Campo Grande - MS.

Albertina Martinez Mitjáns (amitijans@terra.com.br) - Professora Doutora da Faculdade de Educação da Universidade de Brasília - Brasília - DF.

Notas das autoras

'Acessamos a Biblioteca Digital de Teses e Dissertações nos dias: 6, 7 e 8 dez. 2005, 7 mar., 7 jun. e 21 e 23 set. 2006.

${ }^{2}$ Ginzburg (1989) discutiu um paradigma de natureza indiciária, fundamentado na Semiótica, valorizando o aspecto singular, assinalando a importância dos pormenores negligenciáveis no estudo dos fenômenos. Esses argumentos são apoiados nas formas de conhecimento do perito de arte, do detetive e do psicanalista. Nos três tipos de conhecimento, há posturas equivalentes de análise, orientadas para signos (na arte), indícios (na investigação do detetive) e sintomas (na psicanálise). Para maiores aprofundamentos, consultar: GINZBURG, C. Mitos, emblemas, sinais: Morfologia e história. São Paulo: Companhia das Letras, 1989.

274 Deficiência mental e produção científica na base de dados da CAPES: o lugar da aprendizagem • Alexandra Ayach Anache e Albertina Martinez Mitjáns 